\title{
Artificial feeding for a child with a degenerative disorder: a family's view
}

doi: $10.1136 /$ adc. 2004.061440

W e have recently been bereaved of our daughter/granddaughter, who died at the age of 13 in her own home from an undiagnosed neurodegenerative disorder. The last two years of her life were extremely distressing, and we feel strongly that the advice we were given by paediatricians and other professionals involved in her care, did not consider the long term consequences of their recommendations.

Briefly to explain the situation, Frances was initially thought to have cerebral palsy, but she started to show deterioration from the age of 9 or 10 . She was seen by a paediatric neurologist who confirmed that she had a degenerative condition, but was unable to give this condition a name. Her feeding became quite difficult, but her family and known carers were able to give her sufficient food and drink. Unfortunately carers who did not know her so well would be unable to give her sufficient food, and some professionals felt that her deterioration was due to poor nutrition. At this stage, the professionals involved in her care were very insistent that she should be artificially fed. As her close family and predominant carers we were reluctant to agree to this, and felt that we wanted "nature to take its course". Under no circumstances did we want our daughter/granddaughter to be kept alive artificially without any quality of life. We felt pressurised and were made to feel we were not acting in her best interest. It was also said that we could be taken to court if we did not agree. We felt we had no option but to agree to a nasogastric tube for feeding. We were given assurances that she would still be able to take food and drink orally; however, within a month she had ceased to eat anything and was only taking an ounce of fluid. Feeding was something she enjoyed and an important part of family life. From this point it was all downhill, and her quality of life deteriorated dramatically. She had frequent vomits and these often included old blood. She would often vomit up the tube and require replacement tubes. She had to be on a variety of medications to manage her gastric bleeding and vomiting. Her bowel function deteriorated and she required medication and enemas. Her condition continued to deteriorate and the feeding did not reverse any of her problems.

We had not been warned about any of these potential problems. We wish we could have had some written information detailing the consequences, and

It may be that this poignant article is published after those of us in the UK have heard the result of a current appeal to the High Court involving the legality or otherwise of the advice given to doctors by the General Medical Council on withdrawing life prolonging treatments. 'Paediatricians in this country are encouraged to follow a framework devised by the Royal College of Paediatrics and Child Health (RCPCH). ${ }^{2}$

The latter document states: "Feeding is a particularly emotive area for parents and staff and opinions vary regarding withholding and withdrawal of feeding. The role of assisted feeding for an infant or child by nasogastric tube or gastrostomy should be considered very carefully and discussed fully with the family. It may be entirely appropriate, for example, in a child with a swallowing disorder due to a slowly progressive neurodegenerative disease..."

The family in this case were clearly at odds with their doctors over what was best for their child and grandchild and felt dictated to rather than being invited to share decision making. We were not in a position to ask the doctors whether their perception of the situation was different. Did they see themselves as threatening the family with court proceedings or as simply explaining how the law required them to act if they could not reach agreement as to the child's best interests? Would the clinicians concur with the family's view that they did not tell them the disadvantages of artificial feeding?

Whatever the facts of the matter, surely none of us would disagree with the contention that an intervention is not right just because it is possible; that doctors should be open in their discussions with parents; and that professionals should either provide palliative care themselves to the end or show some humility in the face of having to hand it over to another team.

1 General Medical Council. Withholding and withdrawing life-prolonging treatments: good practice in decision-making. London: GMC, 2002 (www.gmc-uk.org).

2 Royal College of Paediatrics and Child Health. Witholding or withdrawing life sustaining treatment in children: a framework for practice, 2 nd edn. London: RCPCH, 2004 (www.rcpch.ac.uk).

possible risks of nasogastric feeding, as this would have reduced the distress we experienced when complications arose. We were fortunate to be referred to a Community Paediatric Palliative Care Team, which has specialist nurses who are available 7 days a week, 24 hours a day. We wish we could have had their support earlier, without which, we would not have been able to continue to care for Frances at home. We managed to prevent hospital admission at any stage in the last two years of her life. They were able to coordinate respite carers and nurses funded by health, social services, and education, as well as providing specialist input from their doctor and nurses experienced in paediatric palliative care. They were able to manage her symptoms so that she was as comfortable as possible, and to provide us with practical support. Their counsellor supported us and this continued after her death.

Her disease continued to progress and by January 2004, she was no longer smiling. This was like a death in itself to us. She was no longer able to even tolerate clear fluids and she died in early February. When she died in my arms, I was telling her how much I loved her and asking for forgiveness. We feel we were left to live with a decision made by professionals who were no longer on the scene, and who no longer had input into her care. What would have been so terrible with letting nature take its course; would it have been less painful, happier, shorter, kinder? We would like the paediatricians and other professionals who advise families on artificial feeding to think about the consequences of their advice. Because a medical intervention is available, it does not always make it right and they need to consider the burden and benefit of any treatment they are recommending. That burden and benefit needs to take into account the whole family and extended carers.

Our plea is that you think and discuss more openly, your recommendations in the future.

\section{ACKNOWLEDGEMENTS}

Dr Nicky King, Medical Director and Megan Watkins, Ellenor Nurse, Ellenor Foundation, East Hill, Dartford, Kent DAl ISA.

The mother and grandmother of Frances Correspondence to: $\mathrm{Dr} \mathrm{H}$ Marcovitch, Syndication Editor, BMJ Publications; h.marcovitch@btinternet.com 